\title{
HUBUNGAN MATRIKS AB DAN BA PADA STRUKTUR JORDAN NILPOTEN
}

\author{
Sondang Purnamasari Pakpahan (sondang@upbjj-ut.ac.id) \\ UPBJJ-UT Medan \\ Elvina Herawaty \\ FMIPA Matematika Universitas Sumatera Utara
}

\begin{abstract}
In this paper, we give another proof about the relationship between $A B$ and $B A$ with eigenvalue zero that reduced by structure Jordan for nilpoten matrix
\end{abstract}

Keywords : eigenvalue, nilpotent matrix, structure Jordan

Perkalian dua matriks kuadrat $A B$ dan $B A$ tidak selalu komutatif, tetapi bukan berarti $A B$ dan $B A$ tidak mempunyai hubungan satu dengan yang lainnya. Salah satu hubungan yang diperoleh melalui

$$
\operatorname{trace}(A B)=\operatorname{trace}(B A)
$$

Hubungan matriks $A B$ dan $B A$ yang lain diperlihatkan oleh Flander (1951), melalui struktur Jordan $A B$ dan $B A$ sebagai berikut:

1. Untuk nilai eigen tak nol, struktur Jordan $A B$ sama dengan struktur Jordan $B A$

2. Untuk nilai eigen nol jika $m_{1} \geq m_{2} \geq \ldots \geq m_{q} \geq 1$ dan $m_{1}+m_{2}+\ldots+m_{q}=m$ ukuranukuran blok Jordan $A B$ dan $n_{1} \geq n_{2} \geq \ldots \geq n_{p} \geq 1$ dengan $n_{1}+n_{2}+\ldots+n_{p}=n$ ukuranukuran blok Jordan $B A$, maka $\left|n_{i}-m_{i}\right| \leq 1$; yaitu struktur Jordan keduanya akan naik sebesar satu atau relatif sama.

Hubungan matrik $A B$ dan $B A$ juga diperlihatkan Flander (1951) dengan menggunakan konsep pembagi nol atas lapangan secara umum, yang relatif abstrak. Thomson (1968) membuktikan pernyataan Flander dengan menggunakan konsep rank dan Parker dan Mitchell (1952) membuktikannya dengan menggunakan konsep variansi, tetapi keduanya tidak memberikan bukti yang transparan.

Dalam teori matriks, struktur Jordan dari suatu matriks nilpoten mempunyai bentuk yang khas, yaitu blok-blok Jordannya berbentuk matriks nilpoten dengan entri satu pada superdiagonal dan entri nol pada posisi lainnya, dan matriks nilpoten mempunyai nilai eigen nol (Horn \& Johnson, 1985).

Melihat pernyataan yang diberikan oleh Horn dan Johnson (1985) untuk matrik nilpoten, maka timbul pertanyaan, apakah pernyataan Flender (1951) yang kedua dapat dibuktikan tanpa menggunakan konsep pembagi nol dan lebih transparan? 
Tulisan ini membahas cara pembuktian yang berbeda tentang hubungan struktur Jordan antara perkalian matriks $A B$ dan $B A$ hanya pada matriks nilpoten.

\section{KONSEP DASAR} berikut :

Struktur Jordan untuk matriks nilpoten diberikan oleh Horn dan Johnson (1985) sebagai

Setiap matriks nilpoten $L_{n \times n}$ berindeks $k$ similar ke bentuk matriks dengan blok- blok diagonal $N=$ $\operatorname{diag}\left(J_{n 1}, J_{n 2}, \ldots, J_{n p}\right)$, yaitu ada matriks invertible $P$ sehingga berlaku

$P^{-1} A P=N=\left[\begin{array}{cccc}J_{n_{1}} & 0 & & 0 \\ 0 & J_{n_{2}} & & 0 \\ & & 0 & \\ 0 & 0 & & J_{n_{p}}\end{array}\right]$ dengan setiap blok $J_{n i}=\left(\begin{array}{ccccc}0 & 1 & 0 & \ldots & 0 \\ 0 & 0 & 1 & \ldots & 0 \\ : & : & & & : \\ 0 & 0 & \ldots & 0 & 1 \\ 0 & 0 & \ldots & 0 & 0\end{array}\right)$

dan $n_{1} \geq n_{2} \geq \ldots \geq n_{p} \geq 1$ dengan $n_{1}+n_{2}+\ldots+n_{p}=n$.

Dalam hal ini berlaku :

1. Jumlah blok di $\mathrm{N}$ sebanyak $n_{p}=\operatorname{dim} \mathrm{N}(L)$

2. Ukuran blok Jordan terbesar di $\mathrm{N}$ adalah $k \times k$

3. Jumlah blok yang berukuran $i x i$ di ditentukan oleh $r_{i-1}-2 r_{i}+r_{i+1}$ dengan $r_{i}=\operatorname{rank}\left(L^{i}\right)$

Contoh : Diberikan matriks $L$ sebagai berikut

$L=\left(\begin{array}{rrrrrr}1 & 1 & -2 & 1 & 1 & -1 \\ 3 & 1 & 5 & 1 & -1 & 3 \\ -2 & -1 & 0 & 0 & -1 & 0 \\ 2 & 1 & 0 & 0 & 1 & 0 \\ -5 & -3 & -1 & -1 & -1 & -1 \\ -3 & -2 & -1 & -1 & 0 & -1\end{array}\right)$ maka L adalah matriks nilpoten berindeks 3

Banyaknya blok $N$ adalah $\operatorname{dim} N(L)=6-\operatorname{rank}(L)=3$.

Dengan $r_{1}=\operatorname{rank}(L)=3 \quad r_{2}=\operatorname{rank}\left(L^{2}\right)=1$ dan $r_{3}=\operatorname{rank}\left(L^{3}\right)=0$.

Banyak blok berukuran $3 \times 3=r_{2}-2 r_{3}+r_{4}=1$, blok berukuran $2 \times 2=r_{1}-2 r_{2}+r_{3}=1$, banyak blok berukuran $1 \times 1=r_{0}-2 r_{1}+r_{2}=0$. 
Oleh karena itu blok Jordan dari $L$ adalah $N=\left(\begin{array}{ccc|cc|c}0 & 1 & 0 & 0 & 0 & 0 \\ 0 & 0 & 1 & 0 & 0 & 0 \\ 0 & 0 & 0 & 0 & 0 & 0 \\ \hline 0 & 0 & 0 & 0 & 1 & 0 \\ 0 & 0 & 0 & 0 & 0 & 0 \\ \hline 0 & 0 & 0 & 0 & 0 & 0\end{array}\right)$

Dari matriks nilpoten $L_{n \times n}$ berindeks $k$ similar ke bentuk matriks dengan blok- blok diagonal $N=\operatorname{diag}\left(\left(J_{n 1}, J_{n 2}, \ldots, J_{n p}\right)\right.$ untuk $n_{1} \geq n_{2} \geq \ldots \geq n_{p} \geq 1, n_{1}+n_{2}+\ldots+n_{p}=n$ diperoleh matriks invertible $P$. Kemudian dibuat matrik $P^{1}$ mxm untuk $m=n+k$ sebagai berikut

$$
P^{1}=P \oplus I=\left[\begin{array}{l|l}
P_{n x n} & 0_{n x k} \\
\hline 0_{k x n} & I_{k x k}
\end{array}\right]
$$

Dalam hal ini matriks $P^{1}$ juga invertible dengan $\left(P^{1}\right)^{-1}=\left[\begin{array}{c|c}\left(P_{n x n}\right)^{-1} & 0_{n x k} \\ \hline 0_{k x n} & I_{k x k}\end{array}\right]$. Jika diberikan $D=\left[\begin{array}{c|c}L_{n x n} & X_{m x k} \\ \hline 0_{k x n} & 0_{k x k}\end{array}\right]$, maka

$\left(P^{\prime}\right)^{-1} D P=\left(\begin{array}{c|c}P^{-1} & 0 \\ \hline 0 & I_{k}\end{array}\right)\left(\begin{array}{c|c}L & X \\ \hline 0 & 0\end{array}\right)\left(\begin{array}{c|c}P & 0 \\ \hline 0 & I_{k}\end{array}\right)=\left(\begin{array}{c|c}P^{-1} A P & P^{-1} X \\ \hline 0 & 0\end{array}\right)=\left(\begin{array}{ccc|c}J_{n_{1}} & 0 & \\ & 0 & \\ 0 & & J_{n_{p}} & \\ \hline 0 & P^{-1} X \\ \hline & 0 & & 0\end{array}\right)\left({ }^{*}\right)$

Karena $D$ berupa matriks nilpoten berarti similar kebentuk matriks blok Jordan, yaitu ada matriks invertible $Q$ sehingga $Q^{-1} D Q=\left(\begin{array}{ccc}J_{m_{1}} & & \\ & 0 & \\ & & J_{m q}\end{array}\right)$

Dengan $m_{1} \geq m_{2} \geq \ldots \geq m_{p} \geq 1, m_{1}+m_{2}+\ldots+m_{q}=m$ $\operatorname{Agar}\left({ }^{*}\right)$ dan $\left({ }^{* *}\right)$ mempunyai bentuk yang sama diperlukan pengertian berikut 1) Jika bentuk $D$ sebagai berikut

$$
\begin{aligned}
& D=\left(\begin{array}{ccc|c}
J_{n_{1}} & & 0 & \\
& 0 & & X \\
0 & & J_{n_{p}} & \\
\hline & 0 & & 0
\end{array}\right) \text { dan dipilih keberadaan } P=\left(\begin{array}{ccc|c}
J_{n_{1}} & & 0 & -W_{1} \\
& 0 & & \\
0 & & J_{n_{p}} & -W_{p} \\
\hline & 0 & & I_{k}
\end{array}\right) \text { dengan } \\
& W_{i}=J_{n_{i}}{ }^{T} X_{i} \text {. Dalam hal ini jelas } P \text { invertibel dan berlaku } P^{-1} D P=\left(\begin{array}{ccc|c}
J_{n_{1}} & & 0 & -Y_{1} \\
& 0 & & \\
0 & & J_{n_{p}} & -Y_{p} \\
\hline & 0 & & 0
\end{array}\right) \\
& \text { dengan } Y_{i}=X_{i}-J_{n_{i}} J_{n_{i}}{ }^{T}
\end{aligned}
$$


Karena $J_{n_{i}} J_{n_{i}}{ }^{T}=I_{n_{i}-1} \oplus 0$ maka setiap blok $n_{i}$ dari matriks $P^{-1} D P$ mempunyai $\quad\left(n_{i}-1\right)$ baris pertama bernilai nol dan pada baris ke- $n_{i}$ entrinya sama seperti $x_{i}$.

2) Pada langkah ini setiap blok $n_{i}$ ambil entri pada baris ke- $i$, kemudian bentuk matriks $R$, yang berarti berukuran $p \times k$.

Matriks $R=\left(\begin{array}{cccc}x_{11} & x_{12} & \ldots & x_{1 k} \\ x_{21} & x_{22} & \ldots & x_{2 k} \\ : & : & & : \\ x_{p 1} & x_{p 2} & \ldots & x_{p k}\end{array}\right)$

Pada matriks $R$ ini dilakukan reduksi baris tanpa melakukan pertukaran baris dan kemudian reduksi kolom, sehingga diperoleh matriks $R$ ' yang berbentuk 0-1 dengan 1 muncul paling banyak satu pada setiap baris dan kolom.

Buat matriks $M$ sebagai berikut

$$
M=\left(\begin{array}{cccc|ccc}
J_{n_{1}} & & & & X_{11} & \cdots & X_{1 q} \\
& J_{n_{2}} & & & X_{21} & \cdots & X_{2 q} \\
& & \ddots & & & & \vdots \\
& & J_{n_{p}} & X_{p 1} & \cdots & X_{p q} \\
\hline & & & J_{m_{1}} & & & \\
& & & & & & \\
& & & & \ddots & \\
& & & & & & J_{m_{q}}
\end{array}\right)
$$

3) Pada matriks $M$ dilakukan

a) menghapus blok baris ke-i dari sebelah atas dan blok kolom ke-i dari sebelah kiri

b) menghapus blok baris ke-j dari sebelah bawah dan blok kolom ke-j dari sebelah kanan.

Maka dari blok entri yang dihapus diperoleh matriks $\left(\begin{array}{cc}J_{n_{i i}} & X_{i j} \\ 0 & J_{m_{j}}\end{array}\right)$ dan $M_{i}$ merupakan submatriks dari $M$ setelah proses pengeliminasian.

Jika $X_{i j}=[0,0, \ldots, 1]^{t}$ dan $J_{m_{j}}=J_{1}$ maka $\left(\begin{array}{cc}J_{n_{i i}} & X_{i j} \\ 0 & J_{m_{j}}\end{array}\right)=\left(\begin{array}{cc}J_{n_{i}} & 1 \\ 0 & J_{1}\end{array}\right) \cong J_{n_{1}+1_{i}}$ Jika $X_{i j}=[0,0, \ldots, 0]^{t}$ maka $\left(\begin{array}{cc}J_{n_{i i}} & X_{i j} \\ 0 & J_{1_{j}}\end{array}\right) \cong J_{n_{i}} \oplus J_{1}$. Artinya jika $\left(\begin{array}{cc}J_{n_{i i}} & X_{i j} \\ 0 & J_{m_{j}}\end{array}\right) \oplus M_{1}=\left(\begin{array}{cc|c}J_{n_{i}} & X_{i j} & 0 \\ 0 & J_{m_{j}} & \\ \hline 0 & M_{1}\end{array}\right)$ maka M similar secara permutasi dengan 


$$
\left(\begin{array}{cc|c}
J_{n_{i}} & X_{i j} & 0 \\
0 & J_{m_{j}} & \\
\hline 0 & M_{1}
\end{array}\right)
$$

Dari 3 langkah observasi dapat dibuat lemma berikut

\section{Lemma :}

Jika A matriks nilopoten $\mathrm{n} \times \mathrm{n}$ dengan blok Jordan $n_{1} \geq n_{2} \geq \ldots \geq n_{p} \geq 1$ untuk $n_{1}+n_{2}+\ldots+n_{p}=n$ dan matriks $\mathrm{D}=\left(\begin{array}{cc}L & X \\ 0 & 0\end{array}\right)$ nilpoten berukuran $\mathrm{m} \times \mathrm{m}$ dengan blok-blok Jordan $m_{1} \geq m_{2} \geq \ldots \geq m_{q} \geq 1$ untuk $m_{1}+m_{2}+\ldots+m_{q}=m$ maka $q \geq p$ dan 1) Blok $m_{i}=1$ untuk $p+1 \leq i \leq q$ 2) $0 \leq m_{i}-n_{i} \leq 1$ untuk $i=1,2, \ldots, p$

Untuk memperlihatkan hubungan struktur Jordan matriks $A B$ yang berukuran $m \times m$ dengan struktur Jordan $B A$ yang berukuran $n \times n$ cukup diasumsikan $A=\left(\begin{array}{ll}I & 0 \\ 0 & 0\end{array}\right)$ dan $B=\left(\begin{array}{ll}B_{11} & B_{12} \\ B_{21} & B_{22}\end{array}\right)$ yang dibawa kebentuk blok matriks yang bersesuaian. diperoleh $A B=\left(\begin{array}{cc}B_{11} & B_{12} \\ 0 & O\end{array}\right)$ dan $B A=\left(\begin{array}{ll}B_{11} & 0 \\ B_{21} & 0\end{array}\right)$. Untuk $A B=\left(\begin{array}{cc}B_{11} & B_{12} \\ 0 & O\end{array}\right)$ dengan $\operatorname{det}(A B-\lambda \mathrm{I})=0$ memberikan nilai eigen $\lambda=0$ atau $\lambda \neq 0$. Untuk $\lambda=0$ maka cukup diasumsikan $B_{11}$ berbentuk matriks nilpoten. Jika diaplikasikan lemma di atas, berarti struktur Jordan $A B$ sama dengan $B A$ atau naik sebesar satu .

\section{PENUTUP}

Hubungan struktur Jordan antara perkalian matriks $A B$ dan $B A$ untuk nilai eigen 0 relatif sama atau berbeda sebesar satu ukuran, dapat diperlihatkan tanpa menggunakan konsep abstrak hanya pada matriks nilpoten. Untuk matriks secara umum bukti di atas tidak berlaku.

\section{REFERENSI}

Flandes, H. (1951). Elementary divisors of $A B$ and BA. Proc. Amer. Math. Soc, 2, 871-874

Horn, R.A. \& Johnson, C.R. (1985). Matrix analysis. New York: Cambridge Univesity Press.

Thompson, R.C. (1968). On the Matrices AB and BA. Linear Algebra Apl, 1, 43-58

Parker, W.V., \& Mitchell (1952). Elementary divisors of certain matrices. Duke Math J, 19, 483-485 